\title{
Management of the sexually abused child
}

\section{David Jones}

This review considers the place of psychiatry in the complex area of management of the sexually abused child. A model is described in order to guide psychiatric perspectives in the field of child sexual abuse, before describing an approach to management in mental health teams.

\section{Definition and scope}

Estimates of the prevalence of child sexual abuse range from $5-30 \%$ of the population, principally because of differences in sampling, interview, and definitions (e.g. inclusion of non-contact abuse). Nevertheless, it is clear that higher rates are found in subsections of the community, including those in contact with psychiatric services.

A working definition is any sexual experience involving physical contact which was against the child's will. Sexual abuse occurs in both boys and girls of all ages. Up to a quarter of the victims are under the age of five. A different response will be required when dealing with infants or teenagers.

\section{Is psychiatric management required?}

Child sexual abuse is perceived to be a problem by various professional groups including the police, civil and criminal courts, child welfare agencies, and mental health professionals, as well as the general public. One difficulty facing professionals is that of appreciating which system of concern they are relating to at any time. From a psychiatric perspective, it can be helpful to distinguish legal and social concerns from psychological.

The social problem of child sexual abuse

The social and legal necessity to manage child sexual abuse derives from a social consensus with several aspects, including an agreement that sexual exploitation of children is morally wrong and that children have 'rights', one of which is to be free from maltreatment of a sexual kind. There is also a shared desire to assure the safety of vulnerable people, including children. Equally, there is agreement that those who violate such a code by abusing children require social control, which introduces the criminal aspect of the problem. Thus several different professionals and social systems are involved in 'managing' sexual abuse, in addition to mental health teams.

\section{The psychology of child sexual abuse}

Mental health teams become involved in managing the problem through the effects of sexual abuse on development and psychological functioning, throughout the life course. There is now strong evidence, confirming clinical impression, of a wide range of psychological symptoms associated with child sexual abuse, appearing both in childhood, and in later adult life (Beitchman et al, 1991; Kendall-Tackettet al, 1993; Mullen et al, 1993) (Boxes 1 and 2).

It is clear, however, that the effects of sexual abuse are inextricably linked with two other important dimensions which are often impossible to separate from sexual trauma itself. These are the context within which sexual abuse occurs, and subsequent life events (Briere \& Runtz, 1988; Beitchman et al, 1992; Mullen et al, 1993; Welch \& Fairburn, 1994; Vize \& Cooper, 1995).

The contextual factors which influence impact include the degree of accompanying family disharmony, any other forms of abuse or neglect, and the presence of a supportive parent or carer at the time of the maltreatment. Subsequent events of crucial importance include the child's own adaptation and method of coping with the abuse, subsequent losses, either through death, family break-up or reception into care, along with subsequent ameliorative effects of school or positive social relationships. Sexual abuse in childhood does not stand alone in terms of its impact, either in childhood or adult life.

Dr Jones is a consultant child and family psychiatrist at Park Hospital for Children, Headington, Oxford OX3 7LQ, and Honorary senior lecturer at the University of Oxford. 
Between half and two-thirds of sexually abused children will suffer moderate to severe psychological ill-effects during the first year after discovery. It is unclear whether initially asymptomatic children will show effects later in their life, but there is growing indication that at least some asymptomatic children develop symptoms in later years, or even adult life. It is not clear whether early intervention in childhood prevents such 'sleeper effects' emerging later on.

Thus it is impossible to conclude the debate about whether all sexually abused children should have some form of mental health intervention, or only the symptomatic. While awaiting further data, it seems reasonable to provide some form of brief intervention for all sexually abused children, reserving more specific interventions for those with symptoms.

Psychiatrists and their teams clearly have a role in relation to this problem, both in childhood and adult years. A range of services will be necessary as the effects are wide-ranging; linked with other factors which deleteriously effect mental health, and occur at various times in the life course. It is also evident that psychiatric teams cannot operate in isolation, but must, of necessity, work with other professionals and systems. Before describing potential psychiatric contributions in more detail, a model through which to organise our contribution is presented.

\section{Developmental psychopathology and child sexual abuse}

There is no single factor, theory, or simple model to explain the occurrence or the effects of child abuse, including sexual abuse. There is broad consensus, however, that models which incorporate the several different factors which have an influence on the occurrence and the impact of maltreatment are the most appropriate (National Research Council, 1993). Within this consensus, two broad themes emerge. The first is the necessity for explanatory models to incorporate the different levels of social complexity which are linked with impact, outcome or causation. These multi-level influences (the ecological approach) can be integrated with developmental ones (Cicchetti, 1989; Belsky, 1993; National Research Council, 1993; Jones, 1995a).

The second theme is the central importance of developmental factors. This approach stresses the fact that the child becomes increasingly organised and more complex as life unfolds. It also recognises the influence of several different levels on child development, ranging from genetic, through physical and psychological influences, to family,

\section{Box 1 Effects in childhood \\ Personality development Self-view \\ Attachments \\ Peer relations \\ Emotional regulation \\ Empathy \\ Affective \\ Post-traumatic states \\ Anxiety disorders \\ Depression \\ Behaviour \\ Conduct disorders \\ Sexualised behaviour \\ Self-destructive \\ Cognitive \\ Educational progress \\ Language development}

neighbourhood and cultural influences. Adaptation is a key principle in developmental theory, so that the child retains integrity of biological functions. A further crucial principle is that once an individual achieves mastery in one area, it paves the way for further progress, both in that area and in other spheres of development. By corollary, pathological development is conceived as a lack of integration, leading to disruption which derails the progress of development. Subsequent influences on the child can be either ameliorating or further potentiate the effect of early damage.

The centre of Fig. 1 shows the immediate context within which the child is cared for, this being one of the most important influences on development. Immediate family influences surround this primary care-taking, and move outwards with increasing social complexity to include school factors, the quality of the child's neighbourhood, his friendships and social contacts and the family's social adaptation or isolation within the community. Surrounding this level of organisation is the influence of the culture within which the family live, including attitudes towards rape, sexual violence and exploitation.

However, as Belsky (1980) emphasised, both child and parent bring their own history to bear upon this contextualised setting, which, via their personality and social functioning, affect the child's appeal and the parent's competence (see Fig. 1). Belsky considers that the weight of parental experiences of childhood is greater than others, within the contextualised model.

Children vary in temperament and with regard to the degree to which they represent a stress factor to their parents. In the field of child sexual abuse, 
the child's own gender can be of great significance, rendering some children more vulnerable. Equally, the timing of the child's birth, or their age at critical times in a family's development, may render them more or less vulnerable to child sexual abuse within the family. Research on abuser's preferences and their selection of children suggests that the child's temperament may influence their vulnerability.

Nonetheless, the quality of caretaking and attachment is of crucial significance both in terms of aetiology and outcome. Thus it is not surprising that maternal support has been consistently linked with outcome; children benefiting from higher levels of maternal support have done better than those without.

\section{Progress after child sexual abuse}

There are a range of intervening variables which influence outcome (see Fig. 1). These include: the individual child's manner of coping and style of adaptation to the maltreatment which they have suffered; parental and family support; system influences, such as the impact of court and other professional procedural interventions. All these factors impact upon the child, and therefore may be considered to be potentially compensatory, or on the other hand, have the potential to worsen outcome for the child. Outcome itself can be considered in terms of the child's behavioural or emotional life, patterns of thinking or their personality and relationships with significant others.

\section{Comprehensive management}

The overall objectives of management of child sexual abuse are directed towards child, family and the child's social context, and comprise the following:

(i) To stop abuse

(ii) To ensure adequate caretaking

(iii) Encouraging positive interpersonal relationships for child and family members

(iv) Management of psychological symptoms and psychiatric disorder

(v) Management of sexually aggressive, violent or exploitative behaviour toward child

This work is undertaken with due regard to the following general considerations.

\section{Paramountcy principle}

The Children Act 1989, placed child welfare directly in the centre of all considerations about children in statute law. This is a helpful principle for all practitioners to adopt, and can be especially helpful for those mental health practitioners who normally work with adults. Jones (1995b) has advocated the adoption of a 'child's eye view', as a means of ensuring that such a child welfare stance is maintained during therapeutic work.

\section{Local and national policy considerations}

All practitioners, including psychiatrists, are committed to working within the spirit of the Government's guidelines, Working Together (Departments of Health, Education and Home Office, 1991) as well as local procedural guidelines, drawn up by each area's Child Protection Committee. Working Together sets out principles and a framework for practice, as well as making specific reference to psychiatric contributions. A linked document (Department of Health, 1994) provides a detailed discussion of medical responsibilities in this area, including confidentiality dilemmas. Broadly, doctors are under an obligation to share any confidential information which they may have when a child is likely to be subject to sexual abuse. Further, this obligation overrides their duty to confidentiality to any other patient (General Medical Council, 1993).

\section{The assessment of risk}

Assessment of risk of sexual maltreatment to the index or any other child continues throughout the period of professional management. This perspective on risk assessment emphasises that ameliorating or compensating factors need to be balanced against factors which potentiate, or raise the risk

\section{Box 2 Effects in adulthood \\ Personality Interpersonal relationships Parenting problems Personality disorders Violence to others Repeat victimisation \\ Affective Depression Post-traumatic states Anxiety disorders \\ Behaviour Self-destructive Alcohol and drug abuse Sexual problems Cognitive} Educational underachievement 


\section{Pre-existing influences Context for abuse}

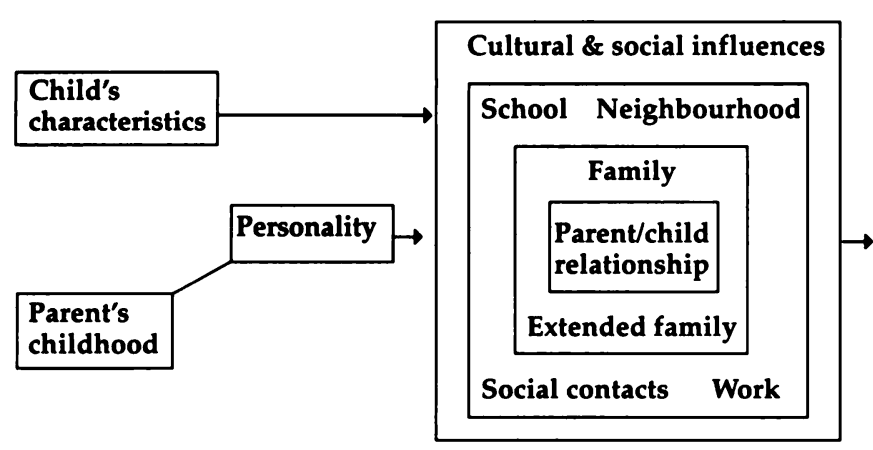

Intervening factors potentiating) (compensatory or

Outcome

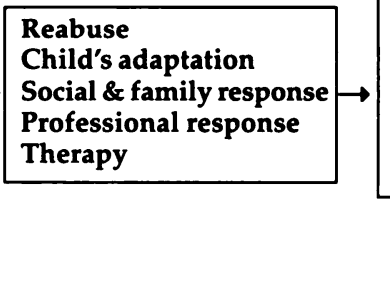

Behaviour
Affective development
Personality
Relationships
Cognitive
Physical sequelae

\section{Fig. 1 Child abuse from the perspective of developmental psychopathology}

of further maltreatment. The domains of risk assessment include: parent; parent/child interaction; child; abuse factors; professional system; family and social setting (Jones, 1991).

\section{Partnership}

Successful management appears to be associated with effective partnership between professionals and their clients. Partnership policies need to include initiatives with children as well as parents. However, partnership is only meaningful in the field of sexual abuse to the extent that it involves a joint focus on the child's welfare and safety, in addition to positive alliances, openness and shared information (Jones, 1995b).

\section{The management of denial}

Denial is common in the field of child sexual abuse. Known abusers, non-abusive caretakers, as well as children themselves, frequently deny the occurrence, or the extent of maltreatment in the immediate aftermath of discovery. Persistent abuser denial may be impossible to deal with in any way except through separation from the child victim. Sometimes, however, denial can be overcome. Pre-treatment group therapy has been used with abusers, in order to improve later takeup and use of therapy. Family approaches which emphasise work on the full disaster of disclosure and address family members' anxieties, rather than require persistent confrontation with the facts may be beneficial (Furniss, 1991).

The link between denial and future propensity to repeat sexual abuse is not straightforward (Scott, 1977; Kennedy \& Grubin, 1992). There is debate as to whether continuing work with abusers under conditions of confidentiality is more effective in overcoming denial than work conducted under the panoply of criminal proceedings. More work is needed in this area in order to offer firm conclusions, but sadly this area is overshadowed by political rhetoric, rather than hard data. Whatever the answers to these and similar questions, the outcome for the abuser is of considerable relevance to the eventual outcome for the sexually abused child.

A substantial minority of victimised children may initially or subsequently deny some or all of the events which occurred. Enabling them to feel less burdened with responsibility for family breakup or sexual activity, and providing support for complex feelings of allegiance to different family members appear key factors in preventing children feeling pressure to recant.

Non-abusive caretakers, frequently mothers, are the most common person to whom a child turns when disclosing abuse. Most mothers are supportive to their children, though mental health professionals are frequently faced with those who are equivocal, or a minority who deny their children's victimisation. Support and understanding for the mother's conflicting allegiances, combined with assistance with her own issues, and support for any abuse which she may have suffered at the hands of the abuser are key factors in enabling mothers to be supportive for their children. This work is of proven value in terms of improved outcome for the child, especially for younger children.

\section{The process of treatment}

The process of treatment can usefully be considered as a three stage sequence comprising: acknowledgement phase; improving parental competence; resolution phase. The model is offered in order to analyse the process of change and assess its 
developmental progression and to specify the changes which are required in order to achieve treatment objectives. It is proposed that the model is not used in a purely linear fashion, because as cases progress, there will be a return to earlier phases in order to re-negotiate them in greater detail.

\section{Acknowledgement phase}

This is much wider than mere admission of culpability. For the abuser it implies taking responsibility for maltreatment and its effects; for the non-abusive carer, evaluation of the child's experience. Both will need to come to terms with any implications of the abuse for their parenting competence. For the child it involves coming to terms with the maltreatment itself and other accompanying aspects such as violence, threat, guilt, secrecy, and any additional, previously undisclosed abuse.

A variety of techniques will probably be necessary to enable individuals and the family to negotiate this phase. Written or taped accounts can facilitate acknowledgement between family members, but care is needed to avoid unexpected episodes of inappropriate pressure being applied to the child, while some family members struggle to resist change. This phase will also include an acknowledgement of other failures of care and parenting competence, in addition to sexual abuse itself.

The work with the child victim during this stage includes helping the child come to terms with the experience of being maltreated, from several different perspectives - the sexual assault, accompanying violence or neglect. Furthermore, the experience of having been exploited and/or threatened may have had significant impact alongside the directly sexual element of the maltreatment. Some children will have been manipulated into reciprocating sexual activities with their abuser or into being involved in abusing other children, at the abuser's behest. Many abusers aim to sexually stimulate the child in order to bolster their own distorted view of the mutuality of child sexual abuse. Thus many victims have guilt ridden memories of having been sexually stimulated by the maltreatment itself, after having been progressively 'groomed' by the abuser, and may thus recall having 'initiated' sexual activities themselves. A simplistic view of the child victim as only on the receiving end of the abuser's attacks, can seriously miss a confusing dilemma with which many children are burdened. This is one of the reasons that this author considers that working solely with 'victims' can be significantly unbalanced. Mental health teams are in a position to work with different family members and to link with those providing treatment for abusers, if not to provide treatment services for abusers themselves, so that a balanced perspective can be maintained.

\section{Improving parental competence}

In cases where parents are fully sensitive and competent, e.g. some extrafamilial child sexual abuse cases, the phase will consist of assisting parents to maintain these qualities in the face of their own trauma and distress (Van Scoyk et al, 1988). Often, however, parental competence is marginal or questionable at the time of disclosure, and this phase will aim to increase care, sensitivity, emotional responsiveness and overall competence with respect to their children, and the degree to which they can meet their children's needs. The enormity of the non-abusive caretakers' trauma and distress at learning that their child has been maltreated, has been underestimated in the past. The aim is to maintain or to improve parental empathy and emotional availability for their children, at a time when they may be overwhelmed with their own distress and emotional needs. Maternal equivocation may be complicated if there has been violence between the adult pair, either sexual or physical, complicating the child sexual abuse presentation. An awareness of the possibility of wider manifestations of family violence is a necessary prerequisite for those providing treatment services for sexually abused children.

The specific approaches used with parents and carers may include individual counselling and therapy, family therapy, marital and couple work, and group treatments. Some parents will need specific interventions if alcohol or substance abuse forms an important element of their problem. Most authorities agree that while a family perspective is crucial, initial work with non-abusive caretakers (usually mothers) and abusers (usually fathers), will need to be orientated towards their distinctive needs. Sexual offender programmes are becoming increasingly established, some linked with the criminal justice system and others orientated towards both those found guilty of criminal offences and those who have not.

Child sexual abuse is often associated with general parenting difficulties, and other forms of abuse and neglect. This will necessitate a broad perspective on parenting being incorporated into treatment plans, because the child's subsequent adjustment, post abuse, depends to such an extent on the availability of parental support. 
Box 3 Contribution of child psychiatric teams

Child and family

Treatment for symptomatic persons

Links with adult and forensic services

Assist with investigation

District level

Liaison with children's homes etc

Training

Research and development

Area Child Protection Committees

Strategic planning

Societal

Public policy

National strategy

Research and teaching

Work with the child during this phase will focus on management and treatment of post-traumatic syndromes, anxiety states, depressive and other emotional disorders, as well as behaviour disturbance. More generally, this phase is one of helping the child to develop an appropriate explanation and internal 'script' of their experience, appropriate to their developmental level. Equally, in relation to the model of abuse effects outlined above, intervention attempts will be focused on the child's peer and social relationships and school functioning, as much as on individual and internal elements of their life.

\section{Resolution phase}

It will either be evident that the child's family context remains an unsafe environment, or is sufficiently functional for the child to remain. From a mental health perspective, relinquishing family bonds is just as important as the re-uniting of families. Both are likely to have significant consequences upon the child's development, and neither can be considered 'better' than the other per se. The determining factor will be the child's welfare, in so far as this can be predicted.

In a large proportion of cases the reuniting option will involve a different family composition from that which existed prior to discovery of abuse. In around half the cases of intrafamilial sexual abuse, the abuser will leave the household. Thus, the reuniting option involves assessing the strength of relationships between the child and other nonabusive family members. Even in these situations parenting competence is sometimes so poor, despite the absence of a direct threat of re-abuse, that alternative placement for the child will prove necessary.

Overall however, the resolution phase marks the start of more adaptive functioning and safe caretaking so far as the child is concerned. In this sense the resolution phase may mark the start of a new phase of professional intervention and is not simply the end of work with a particular child and family.

Alternative care for sexually abused children is not without major difficulties. There are special problems for such children, especially those who show sexual acting out behaviour, in foster care and residential placements.

\section{Treatment planning}

The aim is to specify the focus of treatment by analysing the functional domains which contribute to the risk of recurrence or poor outcome for the child (see risk assessment, above). Once the situation is analysed in this way, positive and negative features of each domain of risk can be noted. Next, the processes whereby change is expected to occur are set out, incorporating all forms of intervention including, but not limited to, specific therapies. The criteria used to assess success should be specified as far as possible at the outset, together with a developmentally appropriate timescale for change.

\section{The contribution of the psychiatric team}

The specific contribution of psychiatric teams depends on local resources, arrangements and working practices, but can be considered in relation to the developmental model already presented (see Box 3).

\section{Specific interventions and efficacy}

Abuse-specific treatment is generally considered to comprise encouraging expression of feelings about abuse, clarifying erroneous beliefs, teaching prevention skills and diminishing the sense of stigma and isolation in victims (Finkelhor \& Berliner, 1995). We cannot yet assert which specific therapies or combination thereof will be effective in the individual case. It seems reasonable to recommend abuse specific counselling for all victims of sexual abuse, combined with supportive counselling for the non-abusive carer. More symptomatic children will require specific interventions. Group treatment may be particularly important for older children and adolescents, 
while individual dynamic therapy shows promise for younger children. Preliminary support exists for use of cognitive behavioural psychotherapy with child victims, especially if combined with parent sessions. In view of the variety of mental health sequelae of child sexual abuse, a variety of available therapies is needed.

Particular challenges for treatment providers include the treatment of sexualised behaviour, the management of disturbed sexually abused children in foster care, and whether asymptomatic children should be in receipt of active therapy or not.

Management of the child and family will need to be integrated with abuser management. Even if the family is not reunited, some of these men will join other family units, presenting a risk to further children. Thus the psychiatry of child sexual abuse work extends into many areas of the field of mental health, notwithstanding this review's focus upon the child and his/her immediate caretaker. The opportunities for prevention, particularly through early intervention, seem to this reviewer to justify high priority for scarce psychiatric resources.

\section{References}

Beitchman, J., Zucker, K., Hood, J., et al (1991) A review of the short term effects of child sexual abuse. Child Abuse and Neglect, 15, 537-556.

,,--- et al (1992) A review of the long term effects of child sexual abuse. Child Abuse and Neglect, 16, 101-118.

Belsky, J. (1980) Child maltreatment: an ecological integration. American Psychologist, 35, 320-335.

- (1993) Etiology of child maltreatment: a developmental/ ecological analysis. Psychological Bulletin, 114, 413-434.

Briere, J. \& Runtz, M. (1988) Symptomatology associated with childhood sexual victimisation in a non-clinical adult sample. Child Abuse and Neglect, 12, 51-59.

Cicchetti, D. (1989) How research on child maltreatment has informed the study of child development: perspectives from developmental psychopathology. In Child Maltreatment: Theory and Research on the Causes and Consequences of Child Abuse and Neglect (eds. D. Cicchetti \& V. Carlson), pp. 377431. Cambridge: Cambridge University Press.

Departments of Health, Education and Home Office (1991) Working Together Under the Children Act 1989. London: HMSO.

- (1994) Child Protection, Medical Responsibilities. London: HMSO.

Finkelhor, D. \& Berliner, L. (1995) Research on the treatment of sexually abused children: a review and recommendations. Journal of the American Academy of Child and Adolescent Psychiatry, 34(11).

Furniss, T. (1991) The Multi-Professional Handbook of Child Sexual Abuse. London: Routledge.

General Medical Council (1993) Revised Guidance on Confidentiality. Amendment to para. 83. London: GMC.

Jones, D. P. H. (1991) The effectiveness of intervention. In Significant Harm (eds M. Adcock, R. White \& A. Hollows), pp 61-84. London: Significant Publications.
- (1995a) Assessment in child sexual abuse. In The Battered Child (eds M. Helfer, R. Kempe \& R. Krugman) (in press). London: University of Chicago Press.

--- (1995b) Treatment of the child and family where maltreatment has occurred. In The Battered Child (eds M. Helfer, R. Kempe \& R. Krugman) (in press). London: University of Chicago Press.

Kendall-Tackett, K., Williams, L. \& Finkelhor, D. (1993) Impact of sexual abuse on children: $A$ review and synthesis of recent empirical studies. Psychological Bulletin, 113, 164-180.

Kennedy, H. G. \& Grubin, D. H. (1992) Patterns of denial in sex offenders. Psychological Medicine, 22, 193-296.

Mullen, P. E., Martin, J. L., Anderson, J. C., et al (1993) Childhood sexual abuse and mental health in adult life. British Journal of Psychiatry, 163, 721-732.

National Research Council (1993) Etiology of Child Maltreatment in Understanding Child Abuse and Neglect, pp. 106-160. Washington, DC: National Academy Press.

Scott, P. D. (1977) Assessing dangerousness in criminals. British Journal of Psychiatry, 131, 127-142.

Van Scoyk, S., Gray, J. \& Jones, D. P. H. (1988) A theoretical framework for evaluation and treatment of the victims of child sexual assault by a non-family member. Family Process, 27, 105-113.

Vize, C. M. \& Cooper, P. J. (1995) Sexual abuse in patients with eating disorder, patients with depression, and normal controls: a comparative study. British Journal of Psychiatry, 167, 80-85.

Welch, S. L. \& Fairburn, C. G. (1994) Sexual abuse and bulimia nervosa: three integrated case control comparisons. American Journal of Psychiatry, 151, 402-407.

\section{Multiple choice questions}

1 Psychological effects associated with childhood sexual abuse include:

a Autism

b Post-traumatic states

c Sexualised behaviour disorder

d Anorexia nervosa

e Post viral fatigue syndrome

2 Components of treatment planning for sexually abused children include:

a A care order

b A risk assessment

c A timetable for expected change

d A child protection plan

e Cognitive behaviour treatment for victims

\section{MCQ answers}

$\begin{array}{lllll}\text { 1 } & & & \text { 2 } & \\ \text { a } & \text { F } & & \text { a } & \text { F } \\ \text { b } & \text { T } & & \text { b } & \text { T } \\ \text { c } & \text { T } & & \text { c } & \text { T } \\ \text { d } & \text { F } & & \text { d } & \text { F } \\ \text { e } & \text { F } & & \text { e } & \text { F }\end{array}$

